\title{
Exon skipping and Duchenne muscular dystrophy: Hope, hype and how feasible?
}

\author{
Steve D. Wilton, Susan Fletcher \\ Centre for Neuromuscular and Neurological Disorders, Molecular Genetic Therapy Group, University of Western Australia, Australia
}

\begin{abstract}
Duchenne muscular dystrophy (DMD), the most common and serious form of childhood muscle wasting is generally caused by protein-truncating mutations in the large DMD gene. Specific removal of an exon from a defective DMD gene transcript has the potential to allow synthesis of a semi-functional dystrophin, thereby reducing the severity and presumably progression of muscle wasting. The efficacy of this treatment will vary greatly between the different mutations that preclude the synthesis of a functional dystrophin. Restoration of the reading frame from a large multi-exon genomic deletion, typically greater than 36 exons, may lead to synthesis of a protein with only partial function and limited clinical benefit, whereas excising a nonsense mutation in a redundant exon should generate a near normal dystrophin. A clinical trial has recently confirmed proof-of-principle that exclusion of Exon 51 from human dystrophin mRNAs, carrying frame-shifting deletions adjacent to this exon, results in dystrophin expression. No major side-effects after local administration of the antisense oligomer were reported. Additional trials are underway, targeting the same exon but using an oligomer of different backbone chemistry. If functional dystrophin synthesis is demonstrated, and safety issues are addressed, subsequent trials will involve systemic delivery. Great challenges are ahead, some technical; establishing an effective delivery regimen, some ethical; choosing subsequent targets for therapy, and others of an administrative and regulatory nature.
\end{abstract}

Key words: Becker muscular dystrophy, clinical trials, Duchenne muscular dystrophy, exon skipping, morpholino oligomer, personalized genetic medicines

\section{Background}

Duchenne and Becker muscular dystrophy (DMD and BMD) are allelic muscle wasting conditions arising from mutations in the large DMD gene at Xp21.2. ${ }^{[1]}$ The most common, serious and progressive form, DMD, is caused by inactivation of the DMD gene product. Affected individuals appear normal at birth and clinical symptoms may be observed between the ages of two to three years. Approximately 50\% of DMD males do not walk until after the age of 18 months, and exhibit signs of retarded motor development, including a waddling gait, difficulty running and jumping and calf enlargement. Muscle wasting is relentlessly progressive in a symmetrical fashion, with joint contractures an important clinical sign. As the process of muscle regeneration becomes overwhelmed, regenerating fibers are less frequent and the replacement with adipose and connective tissue contributes to pseudo-hypertrophy of some muscles. Affected individuals are typically non-ambulant by the age of 12 years, and in some cases as early as seven years (review, ${ }^{[2-4]}$ ). Contractures develop as the disease progresses, and in the absence of optimal care, including corticosteroid treatment, physical therapy and nocturnal assisted ventilation, ${ }^{[5]}$ most patients succumb to the disease by the age of 20 years as the result of respiratory and/or cardiac complications.

In contrast, BMD patients present with a spectrum of severity, from borderline DMD to asymptomatic. ${ }^{[6,7]}$ It has been estimated that BMD occurs at only $10 \%$ the incidence of DMD, most likely through the inability to recognize and diagnose particularly mild cases prior. ${ }^{[4]}$ Although many BMD individuals present with some symptoms between the ages of five to 15 years, by definition a BMD patient will remain ambulant until age 16 years or longer. Some patients despite a deletion within the dystrophin coding sequence, present with no evidence of pathology, or elevated serum creatine kinase, a sensitive marker of muscle damage. ${ }^{[8]}$

The reading frame rule, proposed by Monaco et al., tends to hold true for the majority of DMD and BMD cases. ${ }^{[9,10]}$ Duchenne muscular dystrophy- 
causing mutations, either frame-shifting deletions or duplications, nonsense mutations or splice motif errors lead to the loss of a functional DMD gene product. Becker muscular dystrophy typically results from in-frame deletions in the DMD gene that allow synthesis of an internally truncated, but functional protein..$^{[9,10]}$ The variation in severity reflects the extent and location of the deletion. Large multi-exon deletions or the loss of crucial functional domains typically lead to the more severe phenotype, whereas loss of in-frame exons within the central rod domain appears to have little or no consequences. ${ }^{[11-15]}$ The general rule is that the loss of 36 or more exons is associated with a severe phenotype, regardless of the reading frame, suggesting a minimum size for functional dystrophin. ${ }^{[16]}$ The lack of dystrophin disrupts the link between the actin cytoskeleton and basal lamina, compromising the sarcolemma (review, ${ }^{[17]}$ ). Dystrophic muscle fibers are prone to injury during force generation and repeated damage leads to muscle loss and subsequent fibrosis.

However, rare dystrophin-positive fibers accumulate in muscles of many DMD patients and in animal models of muscular dystrophy. ${ }^{[18-20]}$ This remarkable phenomenon is the result of naturally occurring alternative dystrophin transcripts that bypass the DMD gene lesion. Although the precise mechanism is unknown, the loss of multiple exons from the mRNA, flanking the DMD genomic deletion, has the potential to restore the reading frame of the dystrophin transcript in the revertant fibers. ${ }^{[21-23]}$ In the mdx mouse, an animal model of muscular dystrophy, this mechanism generated in-frame DMD gene transcripts missing multiple exons, typically 20 or more, including Exon 23 that contains the dystrophin inactivating nonsense mutation. ${ }^{[24]}$

The skeletal muscle-specific dystrophin isoform plays a crucial role, stabilizing the sarcolemma ${ }^{[17]}$ through the functional domains, the primary actin-binding sites at the amino terminal encoded by Exons 2, 4 and 5, and weak actin binding between exons 35 and 44, and the cysteine rich $\beta$-dystroglycan binding site encoded by Exons $62-69 .{ }^{[25]}$ The central rod domain appears to be variably dispensable, as demonstrated by the mutations in mildly affected or asymptomatic BMD patients, ${ }^{[6]}$ and the existence of naturally occurring revertant fibers. Hence, a logical strategy to reduce the severity of DMD caused by dystrophin-truncating mutations is to manipulate primary gene transcript processing so as to produce an in-frame mRNA capable of being translated into a functional BMD-like protein. ${ }^{[22]}$

\section{Dystrophin: An Ideal Candidate for Transcript Manipulation}

Manipulation of dystrophin pre-mRNA processing might appear a formidable challenge, considering the size and complexity of expression of this gene. The strategy demands that one or two exons be excluded from a $2.4 \mathrm{Mb}$ DMD gene transcript during the simultaneous expression and processing of thousands of other gene transcripts. However, many DMD gene features that have proved a challenge to cell and gene replacement or repair therapies for DMD are regarded as positive attributes for transcript manipulation, termed 'exon skipping'.

The DMD gene is the largest known and consists of 79 exons spanning some $2.4 \mathrm{Mbp}{ }^{[26]}$ much too large to be incorporated into viral vectors currently available for clinical applications. The wild type protein-coding region is in excess of 11 $\mathrm{Kb}$, incompatible with the capacity of most viral vectors. The identification of a very mildly affected BMD patient with an in-frame deletion of almost half the gene prompted the construction of a vector containing the dystrophin "minigene". ${ }^{[27]}$ Elegant studies have shown that multiple dystrophin domains can be trimmed to create microdystrophin isoforms. ${ }^{[28-30]}$ These constructs are compatible with current viral vectors, lending impetus to gene replacement studies and confirming that there are conditionally redundant domains within the dystrophin protein. ${ }^{[31]}$ Detailed studies have shown that restoration of micro-dystrophin expression at the sarcolemma does not necessarily correlate with functional rescue. ${ }^{[32]}$

Under the control of multiple promoters, the predominant dystrophin transcript is expressed in skeletal muscle as a mature $14 \mathrm{~kb}$ mRNA..$^{[1,25,33]}$ It has been estimated that $16 \mathrm{~h}$ elapse during the processing of a single dystrophin pre-mRNA, during which time 79 exons must be spliced from the primary gene transcript. ${ }^{[34]}$ Possibly because of this major effort in gene processing, the mature DMD gene transcript is present at very low levels and has been estimated to only constitute $0.01-0.001 \%$ of the total mRNA. ${ }^{[35]}$ The full length transcript encodes a protein with four major domains and the reading frame is represented in cartoon form in Figure 1a. The most common type of dystrophin mutation is a deletion of one or more exons, which may disrupt the reading frame with catastrophic consequences. ${ }^{[10,36]}$ However, nonsense mutations where a single base change alters a codon into a premature protein-termination signal [Figure 1b], micro-insertions/deletions to disrupt the reading frame [Figure 1c] or nucleotide changes that disrupt pre-mRNA processing so that an exon is lost, or intronic sequences are retained in the mature mRNA [Figure 1d] have been reported. A BMD-like gene message is depicted in Figure 1e, where the removal of the "END" nonsense mutation, or the "ND" frameshift bypasses the gene lesion, and permits the rest of the gene message to be translated. 


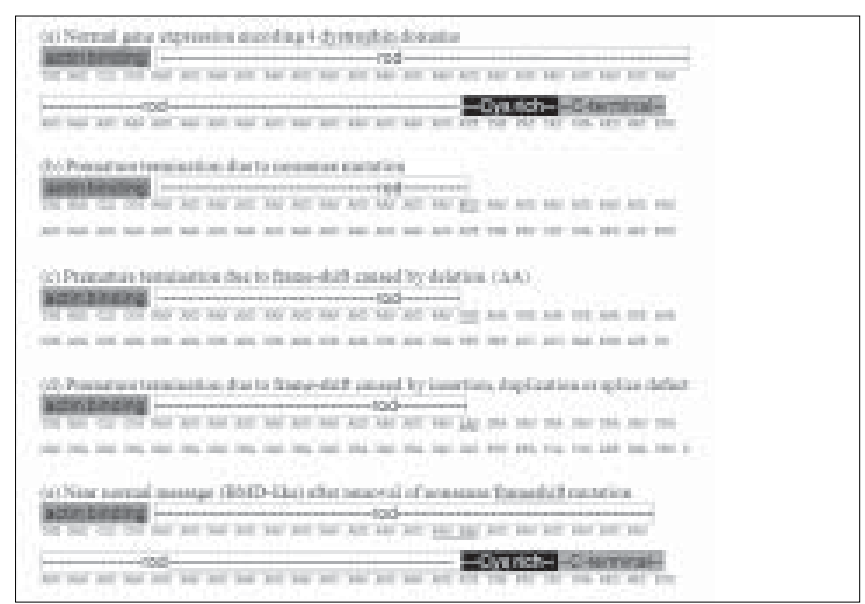

Figure 1: Schematic representation of normal and defective dystrophin transcripts. Crucial functional domains, actin binding and the Cysrich $\beta$-dystroglycan binding domains are represented by gray and black boxes respectively. DMD-causing mutations are indicated by underlining: (b) nonsense, (c) frame-shift deletion and (d) frame-shift insertion. An in-frame deletion, typical of BMD (underlined), and the goal of targeted exon skipping is shown (e)

\section{Targeted Exon Skipping}

Some 15 years ago, Kole and colleagues directed antisense oligomers (AOs) with 2'-O-methyl modified bases on a phosphorothioate backbone (2OMeAOs) to cryptic splice sites that arose from intronic mutations in the $\beta$-globin gene. ${ }^{[37]}$ Upon masking the cryptic splice site, the splicing machinery defaulted to recognition of the normal $\beta$-globin splice sites. Induced dystrophin exon skipping is similar in principle, except that normal splice motifs are targeted to mask the exon from the splicing machinery, leading to exclusion of the exon from the mRNA. In this manner, a nonsense mutation can be removed or the reading frame can be restored around deletions or insertions in the DMD gene transcript. Although exon skipping is the most common consequence of splice motif mutations, some splice defects lead to the activation of one or more cryptic splice sites.

In the golden retriever model of muscular dystrophy (GRMD), ${ }^{[38]}$ the majority of dystrophin transcripts are out-of-frame, since the intron 6 acceptor splice site mutation results in loss of Exon 7 from the mature mRNA. ${ }^{[39]}$ However, sensitive and specific PCR conditions detected near normal length dystrophin transcripts containing all but the first five bases of Exon 7 as some transcripts arose from the recognition of the first AG in Exon 7. ${ }^{[40]}$ Had this transcript been in-frame, it is possible that the severity of the disease may have been mitigated somewhat in these dogs. Human dystrophin splice site mutations and activation of cryptic splice sites have been reported, including one in intron 26 which appears to have arisen independently at least twice (www.dmd.nl). ${ }^{[41]}$

\section{Early studies}

A 2'-O-methyl oligoribonucleotide was designed to target an internal motif in Exon 19 in a cell-free system, ${ }^{[42]}$ followed by skipping of dystrophin Exon 19 using an oligodeoxynucleotide in lymphoblastoid cells. ${ }^{[43]}$ Although the donor and acceptor sites were not targeted, these oligomers induced Exon 19 skipping. These oligomers mimicked the effect of the Kobe DMD mutation, where an intra-exonic deletion removed key splice recognition motifs and led to the omission of Exon 19 from the gene transcript. ${ }^{[44,45]}$ Analysis of the Leiden Muscular Dystrophy Pages (www.dmd.nl) revealed that removal of one of only 12 exons should restore the reading frame in $75 \%$ of dystrophin exon deletion patients. ${ }^{[46]}$ This group reported restoration of the reading frame in a number of different normal and DMD patient cell lines, and most importantly, showed the generation of dystrophin protein by Western blotting and immunofluorescent studies. ${ }^{[47-51]}$

We commenced dystrophin exon skipping studies using the mdx mouse, ${ }^{[52]}$ an animal model carrying a nonsense mutation in dystrophin Exon 23. ${ }^{[53]}$ Although the mdx mouse is commonly referred to as a model of DMD, this is not strictly accurate, since these animals do not present the severe muscle wasting seen in DMD boys. Despite this limitation, the mdx mouse offers an excellent molecular model of a dystrophin mutation, and through detailed histological studies, it is apparent that the diaphragm develops severe dystrophic pathology as the animal ages. ${ }^{[54]}$

We transfected three $2 \mathrm{OMeAO}$ cationic lipoplexes into primary mdx myogenic cells. ${ }^{[55]}$ The scrambled AOs and the oligomer directed at the acceptor splice site had no detectable effect on dystrophin pre-mRNA processing. However, the 20mer directed to the donor site was able to induce Exon 23 skipping in a dosedependent manner. A series of overlapping AOs were subsequently designed to both donor and acceptor sites and, while the acceptor remained an unresponsive target, the efficiency of exon skipping was improved by selecting a 20 mer targeted to the donor site..$^{[56,57]}$ The use of a block, co-polymer F127 resulted in functional amounts of dystrophin expression in the tibialis anterior after intramuscular delivery of the same AO. ${ }^{[58]}$ Other formulations have also been shown to enhance 2OMeAO delivery. ${ }^{[59-61,62]}$

DNA oligomers are of limited potential for induced exon skipping, since this chemistry induces RNase $\mathrm{H}$ activity, leading to mRNA degradation. Perhaps more significantly, oligomers of this chemistry will be rapidly degraded by nucleases. ${ }^{[63]}$ Although $2 \mathrm{OMe}$ AOs have proved most effective, since they are more nuclease resistant and do not support RNaseH activity, several other oligomer chemistries have been evaluated, including peptide nucleic acids (PNAs), ${ }^{[64-66]}$ locked nucleic acids (LNAs), ${ }^{[64,67]}$ 2'- 
O-(2-Methoxy)ethyl-modified (MOE) ${ }^{[65]}$ and phosphorodiamidate morpholino oligomers (PMOs). [68,69] The PNAs were not initially reported to be effective, ${ }^{[64,68]}$ however, a recent report showed some exon skipping. ${ }^{[66]}$ The LNAs induced robust exon skipping, but the exceedingly high Tm indicated great potential for off-target effects due to cross-annealing to related sequences, ${ }^{[64]}$ This group reported that PMOs were not effective and that $2 \mathrm{OMeAOs}$ were the preferred chemistry for clinical application.

\section{Oligomer Delivery}

Although in vitro uptake of $2 \mathrm{OMeAO}$ cationic lipoplexes into myogenic cells is efficient, these compounds have poor uptake in the absence of delivery reagents. To facilitate a comparison between 2OMeAOs and PMOs, we annealed a sense strand leash to the PMO, thereby allowing the duplex to be complexed with a cationic liposome, before transfection into cultured cells. ${ }^{[69]}$ It became apparent that while uncomplexed PMOs were not taken up efficiently in vitro, PMO:leash:cationic lipoplexes induced robust and sustained exon skipping. The PMO uptake by cultured cells after application at high concentrations and scrape loading to facilitate uptake has been reported. ${ }^{[70]}$

We reported that a single intramuscular injection of a PMO in saline was able to induce strong dystrophin expression, six weeks after administration. ${ }^{[68]}$ The compound, injected into 11-day-old mice before the peak of muscle degeneration at 18-21 days, ${ }^{[71]}$ was able to prevent muscle breakdown, as evidenced by normal muscle morphology and a statistically significant reduction in fibers with central nucleation, a marker of muscle regeneration. Subsequent reports showed that systemic delivery of the PMO into the $\mathrm{mdx}$ mouse restored dystrophin expression in skeletal and smooth muscle, although the heart was refractory to treatment. ${ }^{[68,72]}$

A major improvement in the efficacy of exon skipping after systemic delivery was achieved through the use of PMOs coupled to cell-penetrating peptides. ${ }^{[73,74]}$ The ability of PMO-peptide conjugates to induce exon skipping has been demonstrated in vitro, including human and mouse muscle explants, ${ }^{[75]}$ GRMD canine model of muscular dystrophy ${ }^{[76]}$ and the $\operatorname{mdx} 4^{\mathrm{CV}[77]}$ mouse model (Mitrpant, unpublished data). Bodywide dystrophin expression was restored in mdx mice by intraperitoneal administration of the PMO-cellpenetrating peptide $\mathrm{P} 007$ conjugate as four, once-weekly doses of $5 \mathrm{mg} / \mathrm{kg} .{ }^{[73]}$ Although exon skipping was not demonstrated in cardiac muscle, the reduction in skeletal muscle damage lowered the serum creatine kinase to near-normal levels. Recent development of a peptide that mediates PMO-induced exon skipping in cardiac muscle has removed the remaining barrier to effective systemic dystrophin restoration. ${ }^{[78]}$ Numerous peptides were screened in an elegant transgenic mouse model and the most promising candidate was then evaluated for delivery of the PMO targeted to dystrophin Exon 23 in the mdx mouse. There is no evidence of immune responses to the peptides to date (unpublished data), but further investigation into nonspecific or toxic effects is ongoing.

\section{Target Site Selection and Oligomer Design}

Although in vitro studies evaluating human dystrophin exon skipping and work in animal models have proved promising, there are four major challenges to exon skipping therapy for DMD that must be overcome. Achieving effective system delivery has been an obstacle to many nucleic acid therapies, as is selection of an oligomer chemistry that can safely induce sustained re-direction of dystrophin expression after long-term administration. In addition, it will be necessary to design many different oligomers to restore the reading frame around mutations, including non-deletion mutations, across the DMD gene, and undertake safety and toxicology studies.

The oligomers designed to excise selected dystrophin exons in three animal models of muscular dystrophy, mdx and mdx $4^{\mathrm{CV}}$ mice and the GRMD dog, have not provided us with any obvious parameters for optimal targeting. A donor splice site was most amenable when targeting Exon 23 for removal from the mdx mouse DMD gene transcript, while canine dystrophin Exons 6 and 8 were excised by oligomers directed to ESEs and the acceptor site respectively. Mouse dystrophin Exons 52 and 53 could only be efficiently removed using a combination of two and three AOs respectively (unpublished data).

Every dystrophin exon, excluding the first and last, can be excised from the mature human DMD gene transcript. Aartsma Rus and colleagues ${ }^{[47]}$ reported on 114 oligomers that were evaluated for the excision of 35 dystrophin exons. We reported a preliminary draft of AO sequences capable of removing each human dystrophin exon and found that a substantial proportion of compounds could induce some exon skipping, albeit to a variable degree. ${ }^{[79]}$ Some AOs could induce readily detectable exon skipping after in vitro transfection as lipoplexes at concentrations of $10 \mathrm{nM}$, while others induced sporadic or very low levels of exon skipping after administration at $600 \mathrm{nM}$. Clearly, the most applicable compounds for the clinic will be those that are effective at the lowest concentrations, with more easily achievable therapeutic thresholds and lower risk of off-target effects.

We, and others have shown that an oligomer may induce targeted exon skipping, even when the compound includes mismatches. ${ }^{[64,80]}$ We demonstrated 
skipping of Exon 19 from the human and mouse dystrophin transcripts using mismatched AOs, but only at high concentrations. Clearly, cross-reaction to related sequences is a possibility and it will be most important to design effective compounds that excise the target exon at low concentrations. We reported that displacing an oligomer by a few nucleotides dramatically alters exon skipping activity. ${ }^{[80,81]}$

Consequently, we have devoted considerable effort to design oligomers capable of inducing robust exon skipping at low concentrations, and it has become apparent that targeting obvious splice motifs will not guarantee induced exon skipping. ${ }^{[79]}$ Despite early success in excluding Exon 23 from the mouse dystrophin mRNA by targeting the donor splice site, ${ }^{[55-57]}$ directing an oligomer to the identical coordinates in the human DMD gene transcript had no effect on dystrophin processing. ${ }^{[81]}$ Indeed, the human donor splice sites are not generally preferred targets, with only two exons out of the 77 having donor splice sites as the optimal target motif ${ }^{[79]}$ and the majority of exons were efficiently removed by oligomers directed to ESEs, intra exonic motifs that enhance exon recognition. A small number of exons that proved difficult to remove showed satisfactory levels of exon skipping when targeted by combinations of oligomers ${ }^{[82,83]}$ The effect of AO cocktails is clearly synergistic, as particular AOs that are ineffective individually can induce exon skipping when applied at very low concentrations. ${ }^{[83]}$

The AO length emerged as playing an important role in oligo design. In many cases, increasing the length from 25 to 30 nucleotides conferred substantial increases in exon skipping efficiency, far outweighing the additional cost synthesis. ${ }^{[81]}$ Increasing one oligomer from 25 to 30 nucleotides increased exon skipping efficiency fourfold, ${ }^{[81]}$ however, oligomer length must be determined on an exon-by-exon basis. Increasing the length of the oligomer targeting the mouse dystrophin Exon 23 donor site from 25 to 30 bases was counterproductive. Our data suggests that the optimal oligomer length for exon skipping is between 23 and 30 nucleotides, regardless of whether the $2 \mathrm{OMeAO}$ or PMO chemistry is used. ${ }^{[81,83]}$

\section{Exon Skipping: Clinical Implementation}

In the first reported clinical trial of exon skipping for DMD, a DNA oligomer targeted to Exon 19 was administered intravenously to a single DMD patient missing dystrophin Exon 20. ${ }^{[84]}$ Despite showing appropriate dystrophin exon skipping in lymphocytes, induced Exon 19 skipping and restoration of dystrophin synthesis in muscle appeared equivocal. Several parameters could have contributed to this, including the nature of the oligomer chemistry, dosage, timing and duration of the regimen.
More recently, a Phase Ia trial not only addressed the primary safety concerns but also conclusively demonstrated restoration of dystrophin expression in the most common subset of DMD deletion mutation patients. ${ }^{[85]}$ Intramuscular injection of a $2 \mathrm{OMeAO}$ (PRO051) targeted to Exon 51 was carried out in four DMD individuals with different deletions in the major mutation hotspot. Excision of Exon 51 restored the reading frame in all participants, and dystrophin expression was unequivocally demonstrated at the site of injection by immunofluorescence, Western blotting and RNA studies. A Phase I trial of a PMO targeting Exon $51^{[86]}$ is ongoing, and as yet, no data is available. This protocol differs from that by van Deutekom et al., ${ }^{[85]}$ in terms of chemistry, oligomer sequence and target muscle.

\section{Non-deletion Mutations}

Exon skipping development has focused on restoring the reading frame for the most common type of dystrophin mutation: genomic deletions. Exon 51 was selected as the target for the first clinical trial, because removal of this exon would benefit a large percentage of DMD patients. However, exon skipping can be applied to other types of dystrophin mutations, and perhaps it would be more accurate to consider exon skipping as a generic platform of intervention for DMD. Although genomic deletions of one or more exons are the most common DMD-causing mutations, cases arising from exonic duplications, nonsense mutations, splice motif detects, micro-insertions or deletions may be more amenable to exon skipping. Aartsma-Rus and colleagues $^{[87]}$ recently restored the reading frame in DMD patients with genomic duplications. If one copy of a single-exon duplication could be removed, the resultant dystrophin transcript should be translated into a normal protein. Although apparently simplistic, this may prove a technical challenge. It would appear that targeting a duplicated exon generally results in the removal of both exons from the transcript, leading to disruption of the reading frame unless additional exons are removed (Wilton, unpublished observations). ${ }^{[87]}$

Generation of normal transcripts from other DMD dystrophin genes by selected exon exclusion is possible. Pseudo-exon incorporation in the mature DMD gene transcript arises from intronic base changes which activate a set of cryptic splice motifs that meet the criteria for exon recognition. The excessive intronic component of the DMD gene may contribute to the incidence of pseudo-exons as a cause of DMD, reported to occur at a frequency of up to $4 \%{ }^{[88]}$ Despite the rarity of pseudo-exon inclusion, such mutations are perhaps ideal candidates for exon skipping, since exclusion would result in a normal dystrophin mRNA. ${ }^{[88]}$

We reported a novel dystrophin re-arrangement 
involving an un-equal inversion of $28 \mathrm{~kb}$ spanning Exons 49 and 50 that led to the loss of two exons from the mature gene transcript and the variable inclusion of several pseudo-exons from the non-coding strand. ${ }^{[89]}$ Of the two predominantly incorporated pseudo-exons, one was very efficiently excluded by several oligomers targeting various motifs predicted to be involved in exon recognition and incorporation. In contrast, the other commonly incorporated pseudo-exon could not be dislodged from the dystrophin mRNA with any of the oligomers designed to target that exon. However, this recalcitrant pseudo-exon was efficiently removed with an oligomer targeted to the adjacent Exon 51. Clearly, each exon and dystrophin mutation will need to be addressed on a case-by-case basis. While suppression of pseudo-exon inclusion should result in a highly functional dystrophin, protein-truncating defects in the large central rod domain of dystrophin, such as nonsense mutations, micro-insertions or deletions, should also result in near-normal dystrophins. Addressing such mutations in much of the rod domain would only require removal of the defective exon, as exclusion of any exons from 23 to 42 will not disrupt the reading frame, and the loss of an exon in the rod domain would be expected to generate a dystrophin of near-normal function. Few BMD patients have been identified with deletions in this region, implying that such mutations either do not occur, which is unlikely, or manifest as near-normal phenotypes and are not commonly diagnosed.

If exon skipping is considered as a personalized genetic therapy, the frequency of each DMD mutation must not be a parameter in determining which exons should be considered as priority targets. Restoration of the reading frame in some cases of DMD, with a primary gene lesion of the loss of 36 or more exons, may allow eventual synthesis of a dystrophin with normal amino and carboxy termini, but the massive internal deletion results in a heavily compromised dystrophin.

\section{Alternative Exon Skipping Therapies}

One perceived limitation of oligomer-induced exon skipping is the need to periodically re-administer the compound to maintain therapeutic levels of dystrophin. The frequency of re-administration will depend upon many factors; the efficiency of target exon removal, the stability of the oligomer chemistry that determines biological persistence of exon skipping and the functionality of the induced dystrophin in stabilizing the sarcolemma and muscle fiber.

Several approaches to sustained exon skipping without the need for periodic administration of chemically synthesized oligomers are under consideration. Targeted gene modification using a variety of correcting molecules, including chimeric oligomers, ${ }^{\left[{ }^{[0,91]}\right.}$ single- stranded DNA oligomers ${ }^{[92]}$ or PCR fragments through short fragment homologous recombination ${ }^{[93]}$ has been reported. Since exon skipping is generally the most common consequence of splice motif mutations, appropriate and effective induction of mutations in donor or acceptor splice sites could bypass many DMD mutations. Targeted disruption of the intron 22 acceptor splice site, with the aim of excluding Exon 23 has been achieved. ${ }^{\left[{ }^{22]}\right.}$ However, instead of generating precise Exon 23 skipping, multiple transcripts excluding several exons were detected. Oligonucleotide mutagenesis is still under development and is limited by very low rates of DNA modification, particularly in vivo.

Exon skipping has been induced by viral expression cassettes, which promote transcription of antisense sequences. ${ }^{[94-96]}$ Long-term dystrophin expression was demonstrated after systemic delivery of the recombinant adeno-associated virus in the $\mathrm{mdx}$ mouse ${ }^{[95]}$ and in canine muscle ${ }^{[97]}$ and while exceedingly promising, this approach will face the same challenges as conventional gene replacement therapies, including scale-up of production, immune response to the vector and regulatory approval.

Ex vivo genetic transformation of mouse and patient cells with viral expression cassettes tailored to correct the reading frame of the dystrophic line, followed by transplantation, has been reported. ${ }^{[98]}$ The fusion of cell, gene and genetic therapies, while elegant and highly innovative, faces substantial additional challenges resulting from the combined limitations of each strategy.

\section{Summary}

We anticipate that several different clinical trials evaluating induced exon skipping mediated by synthetic oligomers will commence over the next few years, if the current challenges can be adequately addressed. Should oligomer-induced exon skipping be regarded as a platform technology, and the oligomers are considered class-specific compounds, there is the potential to quickly address many different amenable mutations. However, there are few relevant animal models, and the introduction of an oligomer to excise an exon, e.g. dystrophin Exon 51, may induce dystrophic pathology in a normal animal. Similarly, dystrophin Exon 51 skipping cannot be studied in normal human volunteers, since the loss of this exon would lead to DMD. There is general agreement that systemic oligomer delivery is mandatory, however, the most effective compound reported to date, the PMOs coupled to cell-penetrating peptides is yet to be validated in humans. Personalized genetic medicine is an emerging concept, and as such, would be expected to face challenges. The only pharmacological therapy shown to be of benefit to DMD patients, corticosteroid treatment, is beset by significant side-effects and the debate continues 
as to the best administration regimen, even though the commonly used steroids have been clinically available for three decades. We hope that it does not take a similar period of time to establish exon skipping modalities and demonstrate that the AOs can reduce the severity and progression of DMD.

\section{References}

1. Koenig M, Hoffman EP, Bertelson CJ, Monaco AP, Feener C, Kunkel LM. Complete cloning of the Duchenne muscular dystrophy (DMD) cDNA and preliminary genomic organization of the DMD gene in normal and affected individuals. Cell 1987;50:509-17.

2. Emery AE. Clinical and molecular studies in Duchenne muscular dystrophy. Prog Clin Biol Res 1989;306:15-28.

3. Emery AE. The muscular dystrophies. Lancet 2002;359:687-95.

4. Prior TW, Bridgeman SJ. Experience and strategy for the molecular testing of Duchenne muscular dystrophy. J Mol Diagn 2005;7:317-26.

5. Eagle M, Baudouin SV, Chandler C, Giddings DR, Bullock R, Bushby K. Survival in Duchenne muscular dystrophy: Improvements in life expectancy since 1967 and the impact of home nocturnal ventilation. Neuromuscul Disord 2002;12:926-9.

6. Beggs AH, Hoffman EP, Snyder JR, Arahata K, Specht L, Shapiro F, e al. Exploring the molecular basis for variability among patients with Becker muscular dystrophy: dystrophin gene and protein studies. Am J Hum Genet 1991;49:54-67.

7. Comi GP, Prelle A, Bresolin N, Moggio M, Bardoni A, Gallanti A, \&al. Clinical variability in Becker muscular dystrophy: Genetic, biochemical and immunohistochemical correlates. Brain 1994;117:1-14.

8. Schwartz M, Duno M, Palle AL, Krag T, Vissing J. Deletion of exon 16 of the dystrophin gene is not associated with disease. Hum Mutat $2007 ; 28: 205$.

9. Monaco AP, Bertelson CJ, Liechti-Gallati S, Moser H, Kunkel LM. An explanation for the phenotypic differences between patients bearing partial deletions of the DMD locus. Genomics 1988;2:90-5.

10. Koenig M, Beggs AH, Moyer M, Scherpf S, Heindrich K, Bettecken $\mathrm{T}, \mathbb{A}$ al. The molecular basis for Duchenne versus Becker muscular dystrophy: Correlation of severity with type of deletion. Am J Hum Genet 1989;45:498-506.

11. Morandi L, Mora M, Confalonieri V, Barresi R, Di Blasi C, Brugnoni $\mathrm{R}$, \& al. Dystrophin characterization in BMD patients: Correlation of abnormal protein with clinical phenotype. J Neurol Sci 1995;132: $146-55$.

12. Muntoni F, Gobbi P, Sewry C, Sherratt T, Taylor J, Sandhu SK, \& al. Deletions in the 5 ' region of dystrophin and resulting phenotypes. J Med Genet 1994;31:843-7.

13. Novakovic I, Bojic D, Todorovic S, Apostolski S, Lukovic L, Stefanovic $\mathrm{D}$, \& al. Proximal dystrophin gene deletions and protein alterations in Becker muscular dystrophy. Ann N Y Acad Sci 2005;1048:406-10.

14. Beroud C, Tuffery-Giraud S, Matsuo M, Hamroun D, Humbertclaude $\mathrm{V}$, Monnier N, \& al. Multiexon skipping leading to an artificial DMD protein lacking amino acids from exons 45 through 55 could rescue up to $63 \%$ of patients with Duchenne muscular dystrophy. Hum Mutat 2007;28:196-202.

15. Nakamura A, Yoshida K, Fukushima K, Ueda H, Urasawa N, Koyama $J, \notin$ al. Follow-up of three patients with a large in-frame deletion of exons 45-55 in the Duchenne muscular dystrophy (DMD) gene. J Clin Neurosci 2008;15:757-63.

16. Fanin M, Freda MP, Vitiello L, Danieli GA, Pegoraro E, Angelini C. Duchenne phenotype with in-frame deletion removing major portion of dystrophin rod: Threshold effect for deletion size? Muscle Nerve 1996;19:1154-60

17. Chamberlain JS, Corrado K, Rafael JA, Cox GA, Hauser M, Lumeng C. Interactions between dystrophin and the sarcolemma membrane. Soc Gen Physiol Ser 1997;52:19-29.

18. Fanin M, Danieli GA, Cadaldini M, Miorin M, Vitiello L, Angelini C. Dystrophin-positive fibers in Duchenne dystrophy: Origin and correlation to clinical course. Muscle Nerve 1995;18:1115-20.
19. Fanin M, Danieli GA, Vitiello L, Senter L, Angelini C. Prevalence of dystrophin-positive fibers in 85 Duchenne muscular dystrophy patients. Neuromuscul Disord 1992:2:41-5.

20. Sherratt TG, Vulliamy T, Dubowitz V, Sewry CA, Strong PN. Exon skipping and translation in patients with frameshift deletions in the dystrophin gene. Am J Hum Genet 1993;53:1007-15.

21. Schatzberg SJ, Anderson LV, Wilton SD, Kornegay JN, Mann CJ, Solomon GG, \& al. Alternative dystrophin gene transcripts in golden retriever muscular dystrophy. Muscle Nerve 1998;21:991-8.

22. Wilton SD, Dye DE, Blechynden LM, Laing NG. Revertant fibres: A possible genetic therapy for Duchenne muscular dystrophy? Neuromuscul Disord. 1997;7:329-35.

23. Wilton SD, Dye DE, Laing NG. Dystrophin gene transcripts skipping the mdx mutation. Muscle Nerve 1997;20:728-34.

24. Lu QL, Morris GE, Wilton SD, Ly T, Artemyeva OV, Strong P, \& al. Massive idiosyncratic exon skipping corrects the nonsense mutation in dystrophic mouse muscle and produces functional revertant fibers by clonal expansion. J Cell Biol 2000;148:985-96.

25. Koenig M, Monaco AP, Kunkel LM. The complete sequence of dystrophin predicts a rod-shaped cytoskeletal protein. Cell 1988;53:219-28.

26. Roberts RG, Coffey AJ, Bobrow M, Bentley DR. Exon structure of the human dystrophin gene. Genomies 1993;16:536-8.

27. England SB, Nicholson LV, Johnson MA, Forrest SM, Love DR, Zubrzycka-Gaarn EE, \& al. Very mild muscular dystrophy associated with the deletion of $46 \%$ of dystrophin. Nature 1990;343:180-2.

28. Odom GL, Gregorevic P, Chamberlain JS. Viral-mediated gene therapy for the muscular dystrophies: Successes, limitations and recent advances. Biochim Biophys Acta 2007;1772:243-62.

29. Yuasa K, Yoshimura M, Urasawa N, Ohshima S, Howell JM, Nakamura $\mathrm{A}, \mathbb{e}$ al. Injection of a recombinant $\mathrm{AAV}$ serotype 2 into canine skeletal muscles evokes strong immune responses against transgene products. Gene Ther 2007;14:1249-60.

30. Gregorevic P, Allen JM, Minami E, Blankinship MJ, Haraguchi M, Meuse L, \& al. rAAV6-microdystrophin preserves muscle function and extends lifespan in severely dystrophic mice. Nat Med 2006;12:787-9.

31. Corrado K, Mills PL, Chamberlain JS. Deletion analysis of the dystrophin-actin binding domain. FEBS Lett 1994;344:255-60.

32. Banks GB, Gregorevic P, Allen JM, Finn EE, Chamberlain JS. Functional capacity of dystrophins carrying deletions in the N-terminal actin-binding domain. Hum Mol Genet 2007;16:2105-13

33. Monaco AP. Dystrophin, the protein product of the Duchenne/Becker muscular dystrophy gene. Trends Biochem Sci 1989;14:412-5.

34. Tennyson CN, Klamut HJ, Worton RG. The human dystrophin gene requires 16 hours to be transcribed and is cotranseriptionally spliced. Nat Genet 1995;9:184-90.

35. Chelly J, Kaplan JC, Maire P, Gautron S, Kahn A. Transcription of the dystrophin gene in human muscle and non-muscle tissue. Nature 1988:333:858-60.

36. Den Dunnen JT, Grootscholten PM, Bakker E, Blonden LA, Ginjaar HB, Wapenaar MC, \& al. Topography of the Duchenne muscular dystrophy (DMD) gene: FIGE and cDNA analysis of 194 cases reveals 115 deletions and 13 duplications. Am J Hum Genet. 1989;45:835-47.

37. Dominski Z, Kole R. Restoration of correct splicing in thalassemic pre-mRNA by antisense oligonucleotides. Proc Natl Acad Sci USA 1993;90:8673-7.

38. Kornegay JN, Tuler SM, Miller DM, Levesque DC. Muscular dystrophy in a litter of golden retriever dogs. Muscle Nerve 1988;11:1056-64.

39. Sharp NJ, Kornegay JN, Van Camp SD, Herbstreith MH, Secore SL, Kettle S, \& al. An error in dystrophin mRNA processing in golden retriever muscular dystrophy, an animal homologue of Duchenne muscular dystrophy. Genomics 1992;13:115-21.

40. Fletcher S, Ly T, Duff RM, Mc CH, Wilton SD. Cryptic splicing involving the splice site mutation in the canine model of Duchenne muscular dystrophy. Neuromuscul Disord 2001;11:239-43.

41. Wilton SD, Chandler DC, Kakulas BA, Laing NG. Identification of a point mutation and germinal mosaicism in a Duchenne muscular dystrophy family. Hum Mutat 1994;3:133-40.

42. Takeshima Y, Nishio H, Sakamoto H, Nakamura H, Matsuo M. Modulation of in vitro splicing of the upstream intron by modifying an intra-exon sequence which is deleted from the dystrophin gene in 
dystrophin Kobe. J Clin Invest 1995;95:515-20.

43. Pramono ZA, Takeshima Y, Alimsardjono H, Ishii A, Takeda S, Matsuo M. Induction of exon skipping of the dystrophin transcript in lymphoblastoid cells by transfecting an antisense oligodeoxynucleotide complementary to an exon recognition sequence. Biochem Biophys Res Commun 1996;226:445-9.

44. Matsuo M, Masumura T, Nakajima T, Kitoh Y, Takumi T, Nishio $\mathrm{H}$, $\notin$ al. A very small frame-shifting deletion within exon 19 of the Duchenne muscular dystrophy gene. Biochem Biophys Res Commun 1990; 170:963-7.

45. Matsuo M, Masumura T, Nishio H, Nakajima T, Kitoh Y, Takumi T, \& al. Exon skipping during splicing of dystrophin mRNA precursor due to an intraexon deletion in the dystrophin gene of Duchenne muscular dystrophy kobe. J Clin Invest 1991;87:2127-31.

46. Aartsma-Rus A, Bremmer-Bout M, Janson AA, den Dunnen JT, van Ommen G.J, van Deutekom JC. Targeted exon skipping as a potential gene correction therapy for Duchenne muscular dystrophy. Neuromuscul Disord 2002;12:S71-7.

47. Aartsma-Rus A, De Winter CL, Janson AA, Kaman WE, Van Ommen GJ, Den Dunnen JT, \& al. Functional analysis of 114 exon-internal AONs for targeted DMD exon skipping: Indication for steric hindrance of SR protein binding sites. Oligonucleotides 2005;15:284-97.

48. Aartsma-Rus A, Janson AA, Heemskerk JA, De Winter CL, Van Ommen GJ, Van Deutekom JC. Therapeutic modulation of DMD splicing by blocking exonic splicing enhancer sites with antisense oligonucleotides. Ann N Y Acad Sci 2006;1082:74-6.

49. Aartsma-Rus A, Janson AA, Kaman WE, Bremmer-Bout M, den Dunnen JT, Baas F, \& al. Therapeutic antisense-induced exon skipping in cultured muscle cells from six different DMD patients. Hum Mol Genet 2003;12:907-14.

50. Aartsma-Rus A, Janson AA, Kaman WE, Bremmer-Bout M, van Ommen GJ, den Dunnen JT, \& al. Antisense-induced multiexon skipping for Duchenne muscular dystrophy makes more sense. Am J Hum Genet 2004;74:83-92.

51. Aartsma-Rus A, van Ommen GJ. Antisense-mediated exon skipping: A versatile tool with therapeutic and research applications. RNA 2007;13:1609-24.

52. Bulfield G, Siller WG, Wight PA, Moore KJ. X chromosome-linked muscular dystrophy $(\mathrm{mdx})$ in the mouse. Proc Natl Acad Sci USA 1984;81:1189-92.

53. Sicinski P, Geng Y, Ryder-Cook AS, Barnard EA, Darlison MG, Barnard PJ. The molecular basis of muscular dystrophy in the mdx mouse: A point mutation. Science 1989;244:1578-80.

54. Stedman HH, Sweeney HL, Shrager JB, Maguire HC, Panettieri RA, Petrof $\mathrm{B}, \mathrm{A}$ al. The mdx mouse diaphragm reproduces the degenerative changes of Duchenne muscular dystrophy. Nature 1991;352:536-9.

55. Wilton SD, Lloyd F, Carville K, Fletcher S, Honeyman K, Agrawal $\mathrm{S}$, \& al. Specific removal of the nonsense mutation from the $\mathrm{mdx}$ dystrophin mRNA using antisense oligonucleotides. Neuromuscul Disord 1999;9:330-8.

56. Mann CJ, Honeyman K, Cheng AJ, Ly T, Lloyd F, Fletcher S, \& al. Antisense-induced exon skipping and synthesis of dystrophin in the $\mathrm{mdx}$ mouse. Proc Natl Acad Sci USA 2001;98:42-7.

57. Mann CJ, Honeyman K, McClorey G, Fletcher S, Wilton SD. Improved antisense oligonucleotide induced exon skipping in the mdx mouse model of muscular dystrophy. J Gene Med 2002;4:644-54.

58. Lu QL, Mann CJ, Lou F, Bou-Gharios G, Morris GE, Xue SA, \& al. Functional amounts of dystrophin produced by skipping the mutated exon in the mdx dystrophic mouse. Nat Med 2003;9:1009-14.

59. Sirsi SR, Williams JH, Lutz GJ. Poly(ethylene imine)-poly(ethylene glycol) copolymers facilitate efficient delivery of antisense oligonucleotides to nuclei of mature muscle cells of mdx mice. Hum Gene Ther 2005:16:1307-17.

60. Williams JH, Sirsi SR, Latta DR, Lutz GJ. Induction of dystrophin expression by exon skipping in mdx mice following intramuscular injection of antisense oligonucleotides complexed with PEG-PEI copolymers. Mol Ther 2006;14:88-96.

61. Wells KE, Fletcher S, Mann CJ, Wilton SD, Wells DJ. Enhanced in vivo delivery of antisense oligonucleotides to restore dystrophin expression in adult mdx mouse muscle. FEBS Lett 2003;552:145-9.
62. Rando TA. Non-viral gene therapy for Duchenne muscular dystrophy: progress and challenges. Biochim Biophys Acta 2007;1772:263-71.

63. Crooke ST. Molecular mechanisms of action of antisense drugs. Biochim Biophys Acta 1999;1489:31-44.

64. Aartsma-Rus A, Kaman WE, Bremmer-Bout M, Janson AA, den Dunnen JT, van Ommen GJ, \& al. Comparative analysis of antisense oligonucleotide analogs for targeted DMD exon 46 skipping in muscle cells. Gene Ther 2004;11:1391-8.

65. Sazani P, Gemignani F, Kang SH, Maier MA, Manoharan M, Persmark $\mathrm{M}, \notin$ al. Systemically delivered antisense oligomers upregulate gene expression in mouse tissues. Nat Biotechnol 2002;20:1228-33.

66. Yin H, Lu Q, Wood M. Effective exon skipping and restoration of dystrophin expression by peptide nucleic acid antisense oligonucleotides in mdx mice. Mol Ther 2008;16:38-45.

67. Braasch DA, Liu Y, Corey DR. Antisense inhibition of gene expression in cells by oligonucleotides incorporating locked nucleic acids: Effect of mRNA target sequence and chimera design. Nucleic Acids Res 2002;30:5160-7.

68. Fletcher S, Honeyman K, Fall AM, Harding PL, Johnsen RD, Wilton SD. Dystrophin expression in the mdx mouse after localised and systemic administration of a morpholino antisense oligonucleotide. J Gene Med $2006 ; 8: 207-16$

69. Gebski BL, Mann CJ, Fletcher S, Wilton SD. Morpholino antisense oligonucleotide induced dystrophin exon 23 skipping in mdx mouse muscle. Hum Mol Genet 2003;12:1801-11.

70. Schmajuk G, Sierakowska H, Kole R. Antisense oligonucleotides with different backbones. Modification of splicing pathways and efficacy of uptake. J Biol Chem 1999;274:21783-9.

71. Muntoni F, Mateddu A, Marchei F, Clerk A, Serra G. Muscular weakness in the mdx mouse. J Neurol Sci 1993;120:71-7.

72. Alter J, Lou F, Rabinowitz A, Yin H, Rosenfeld J, Wilton SD, \& al. Systemic delivery of morpholino oligonucleotide restores dystrophin expression bodywide and improves dystrophic pathology. Nat Med 2006;12:175-7.

73. Fletcher S, Honeyman K, Fall AM, Harding PL, Johnsen RD, Steinhaus $J P, \notin a l$. Morpholino oligomer-mediated exon skipping averts the onset of dystrophic pathology in the mdx mouse. Mol Ther 2007;15:1587-92.

74. Moulton HM, Fletcher S, Neuman BW, MeClorey G, Stein DA, Abes S, \& al. Cell-penetrating peptide-morpholino conjugates alter pre-mRNA splicing of DMD (Duchenne muscular dystrophy) and inhibit murine coronavirus replication in vivo. Biochem Soc Trans 2007;35:826-8.

75. McClorey G, Fall AM, Moulton HM, Iversen PL, Rasko JE, Ryan M, \& al. Induced dystrophin exon skipping in human muscle explants. Neuromuscul Disord 2006;16:583-90.

76. McClorey G, Moulton HM, Iversen PL, Fletcher S, Wilton SD. Antisense oligonucleotide-induced exon skipping restores dystrophin expression in vitro in a canine model of DMD. Gene Ther 2006;13:1373-81.

77. Im WB, Phelps SF, Copen EH, Adams EG, Slightom JL, Chamberlain JS. Differential expression of dystrophin isoforms in strains of mdx mice with different mutations. Hum Mol Genet 1996;5:1149-53.

78. Jearawiriyapaisarn N, Moulton HM, Buckley B, Roberts J, Sazani P, Fucharoen S, \& al. Sustained dystrophin expression induced by peptideconjugated morpholino oligomers in the muscles of mdx Mice. Mol Ther 2008; In press.

79. Wilton SD, Fall AM, Harding PL, MeClorey G, Coleman C, Fletcher $\mathrm{S}$. Antisense oligonucleotide-induced exon skipping across the human dystrophin gene transcript. Mol Ther 2007;15:1288-96.

80. Errington SJ, Mann CJ, Fletcher S, Wilton SD. Target selection for antisense oligonucleotide induced exon skipping in the dystrophin gene. $\mathrm{J}$ Gene Med 2003;5:518-27.

81. Harding PL, Fall AM, Honeyman K, Fletcher S, Wilton SD. The influence of antisense oligonucleotide length on dystrophin exon skipping. Mol Ther 2006;15:157-66.

82. Aartsma-Rus A, Kaman WE, Weij R, den Dunnen JT, van Ommen GJ, van Deutekom JC. Exploring the frontiers of therapeutic exon skipping for Duchenne muscular dystrophy by double targeting within one or multiple exons. Mol Ther 2006;14:401-7.

83. Adams AM, Harding PL, Iversen PL, Coleman C, Fletcher S, Wilton SD. Antisense oligonucleotide induced exon skipping and the dystrophin gene transcript: Cocktails and chemistries. BMC Mol Biol 2007;8:57. 
84. Takeshima Y, Yagi M, Wada H, Ishibashi K, Nishiyama A, Kakumoto M, e al. Intravenous infusion of an antisense oligonucleotide results in exon skipping in muscle dystrophin mRNA of Duchenne muscular dystrophy. Pediatr Res 2006;59:690-4.

85. van Deutekom JC, Janson AA, Ginjaar IB, Frankhuizen WS, AartsmaRus A, Bremmer-Bout M, \& al. Local dystrophin restoration with antisense oligonucleotide PRO051. N Engl J Med. 2007;357:2677-86.

86. Arechavala-Gomeza V, Graham IR, Popplewell LJ, Adams AM, AartsmaRus A, Kinali M, đal. Comparative analysis of antisense oligonucleotide sequences for targeted skipping of exon 51 during dystrophin Pre-mRNA splicing in human muscle. Hum Gene Ther 2007.

87. Aartsma-Rus A, Janson AA, van Ommen GJ, van Deutekom JC. Antisense-induced exon skipping for duplications in Duchenne muscular dystrophy. BMC Med Genet 2007;8:43.

88. Gurvich OL, Tuohy TM, Howard MT, Finkel RS, Medne L, Anderson $\mathrm{CB}$, \& al. DMD pseudoexon mutations: Splicing efficiency, phenotype and potential therapy. Ann Neurol 2008;63:81-9.

89. Madden H, Fletcher S, Davis M, Wilton SD. Characterisation of a complex DMD-causing dystrophin gene inversion and restoration of the reading frame by induced exon skipping. Hum Mutat 2008; in press.

90. Cole-Strauss A, Yoon K, Xiang Y, Byrne BC, Rice MC, Gryn J, \& al. Correction of the mutation responsible for sickle cell anemia by an RNADNA oligonucleotide. Science 1996;273:1386-9.

91. Kmiec EB. Genomic targeting and genetic conversion in cancer therapy. Semin Oncol 1996;23:188-93.

92. Bertoni C, Lau C, Rando TA. Restoration of dystrophin expression in mdx muscle cells by chimeraplast-mediated exon skipping. Hum Mol Genet 2003;12:1087-99.

93. Kapsa RM, Quigley AF, Vadolas J, Steeper K, Ioannou PA, Byrne E, \&al. Targeted gene correction in the mdx mouse using short DNA fragments: towards application with bone marrow-derived cells for autologous remodeling of dystrophic muscle. Gene Ther 2002;9:695-9.

94. Goyenvalle A, Vulin A, Fougerousse F, Letureq F, Kaplan JC, Garcia L \& al. Rescue of dystrophic muscle through U7 snRNA-mediated exon skipping. Science 2004;306:1796-9.

95. Denti MA, Rosa A, D'Antona G, Sthandier O, De Angelis FG, Nicoletti $\mathrm{C}, \mathbb{A}$ al. Body-wide gene therapy of Duchenne muscular dystrophy in the mdx mouse model. Proc Natl Acad Sci USA 2006;103:3758-63.

96. Denti MA, Rosa A, D'Antona G, Sthandier O, De Angelis FG, Nicoletti $\mathrm{C}, \notin$ al. Chimeric adeno-associated virus/antisense U1 small nuclear RNA effectively rescues dystrophin synthesis and muscle function by local treatment of mdx mice. Hum Gene Ther 2006;17:565-74.

97. Vulin A, Goyenvalle A, Barthelemy I, Letureq F, Kaplan JC, Chelly J. Rescue of dystrophin in the GRMD dog by multiexon skipping using engineered U7 snRNAs. Neuromuscul Disord 2006;16:722-3.

98. Quenneville SP, Chapdelaine P, Skuk D, Paradis M, Goulet M, Rousseau J, \& al. Autologous transplantation of muscle precursor cells modified with a lentivirus for muscular dystrophy: Human cells and primate models. Mol Ther 2007;15:431-8.

Accepted on 24-07-2008

Source of Support: Muscular Dystrophy Association (USA) (MDA 4352), National Institutes of Health (RO1 NS044146-02),

Muscular Dystrophy Association Western Australia (Inc), Charley's

Fund, Gavriel Mier Trust, James and Mathew Foundation, Medical and Health Research Infrastructure Fund (Western Australia),

Conflict of Interest: None declared. 
Copyright of Neurology India is the property of Medknow Publications Pvt. Ltd. and its content may not be copied or emailed to multiple sites or posted to a listserv without the copyright holder's express written permission. However, users may print, download, or email articles for individual use. 